\title{
Association between myocardial mechanical dispersion and ventricular arrhythmogenicity in Chagas cardiomyopathy.
}

Alda Cristina Alves de Azevedo ( $\sim$ aldacaazevedo@yahoo.com.br)

federal university of minas gerais https://orcid.org/0000-0003-2633-4909

Marcio Vinicius Lins Barros

Universidade Federal de Minas Gerais

Lars Gunnar Klaboe

university of oslo

\section{Thor Edvardsen}

university of oslo

\section{Henrique Silveira Costa}

Universidade Federal de Minas Gerais

\section{Gabriela Miana de Mattos Paixao}

Federal University of Minas Gerais: Universidade Federal de Minas Gerais

Omar Ribeiro Santos Junior

Federal University of Minas Gerais: Universidade Federal de Minas Gerais

Maria do Carmo Pereira Nunes

Federal University of Minas Gerais: Universidade Federal de Minas Gerais

Manoel Otavio da Costa Rocha

Federal University of Minas Gerais: Universidade Federal de Minas Gerais

\section{Research Article}

Keywords: Chagas disease, Chronic Chagas cardiomyopathy, Arrhythmia, Mechanical myocardial dispersion, Two-dimensional strain

Posted Date: February 18th, 2021

DOI: https://doi.org/10.21203/rs.3.rs-158680/v1

License: (c) (1) This work is licensed under a Creative Commons Attribution 4.0 International License.

Read Full License 
Version of Record: A version of this preprint was published at The International Journal of Cardiovascular Imaging on April 21st, 2021. See the published version at https://doi.org/10.1007/s10554-021-02246-8. 


\section{Abstract}

Endemic Chagas diseaseis a major health concernin LatinAmerica. Ventricular arrhythmias (VA) is a hallmark of Chagas cardiomyopathy (ChC) associated with worse prognosis. To verify if there is an association between myocardial mechanical dispersion and ventricular arrhythmogenicity in CCM. This is a cross-sectional study involving 77 patients with CCM. Global longitudinal strain (GLS) and MD were evaluated by echocardiogram, derived from the speckle tracking technique. Myocardial MD was measured from the onset of the Q / $R$ wave on electrocardiogram to the peak longitudinal strain in 16 segments of the left ventricle. Frequency and complexity of ventricular extrasystoles (VES) were assessed by dynamic electrocardiography. The density and complexity of VES and the presence of non-sustained ventricular tachycardias (NSVTs) increase as MD increases. In logistic regression, MD was the only variable associated with the presence of VES in pairs and bigeminy. In the univariate analysis, both MD and GLS were associated with the presence of NSVT (both, $p<0.01$ ), and MD was independently associated with NSVT (OR 1.04, 95\% Cl: 1.004-1.201, $p=0.031$ ). In Chagas cardiomyopathy, MD is associated with a higher density and complexity of ventricular extrasystoles, including NSVT.

\section{Introduction}

Chagas disease is an important public health problem in Latin America, affecting about eight million people ${ }^{1,2}$, with a significant medical-social impact, even today. Its clinical evolution is quite variable, and several patients may remain asymptomatic for a long time. However, about $20 \%$ to $30 \%$ of infected patients develop the cardiac form of the disease, which is manifested by the presence of several types of conduction disorders such as cardiac insufficiency, arrhythmias, thromboembolism and sudden death, this being the main cause of death in this form of the disease $3,4,5$.

Chagas cardiomyopathy is the most important manifestation of Chagas disease ${ }^{4,6}$. It is characterized by the presence of a dilated ventricular cavity, associated with systolic dysfunction. It has some important peculiarities, which distinguish it from heart diseases of other etiologies ${ }^{7}$. Among them, the following are highlighted: high and complex arrhythmogenicity, high frequency of sudden death, worse diagnosis, its continuous inflammatory and fibrosing nature and denervation of the intrinsic nervous system of the heart. $8,9,10,11,12$.

The mechanism of ventricular arrythmia in this condition is related to inflammatory myocarditis $3,13,14,15,16$, which creates the substrate for arrhythmogenicity $13,17,18$. Previous studies have shown that fibrosis is present in patients with Chagas cardiomyopathy and that the extension of the fibrosis in myocardial magnetic resonance imaging is correlated to the risk for arrythmias ${ }^{19}$. In addition to this fibrotic substrate, electric dispersion is caused by areas of slow conduction, leading to electric instability 20,21 . Myocardial fibrosis and the areas of slow conduction result in mechanical changes, both in length and function. Thus, regional differences in electrical properties may cause heterogeneity of myocardial contraction, a condition known as mechanical dispersion ${ }^{22,23}$. 
Bidimensional strain is an excellent tool for the assessment of global and segmental ventricular function 24. Myocardial MD by strain is a sensitive measure of heterogeneity of ventricular contraction and, in recent studies, it has been shown to predict ventricular arrhythmias in patients with idiopathic dilated cardiomyopathy ${ }^{25}$ and after the myocardial infarction ${ }^{23}$. There are few studies in the literature relating mechanical dispersion to myocardial fibrosis ${ }^{26}$ and the method is still little studied in patients with Chagas cardiomyopathy ${ }^{27}$, despite its high arrhythmogenicity.

In this study, we support the hypothesis that the higher the mechanical dispersion, the higher the arrhythmogenicity in CCM. Thus, our objective is to verify whether the myocardial MD is associated with the density and complexity of ventricular arrhythmia of this condition.

\section{Methods}

This cross-sectional study included patients with CCM selected at Centro de Referência e Treinamento para Tratamento de Doenças Infecciosas e Parasitárias (Reference and Training Center for the Treatment of Infectious and Parasitic Diseases) of Universidade Federal de Minas Gerais (Federal University of Minas Gerais) from March 2016 to August 2017. Groups have not been compared. The correlation among mechanical dispersion, echocardiographic variables (LVEF; LVDd, LVSd, E/e' ratio and GLS) and frequency and complexity of ventricular extrasystoles, which were recorded on the dynamic electrocardiography has been studied. Then they have been divided in quartiles, according to the value of mechanical dispersion and the correlation analysis was performed with echocardiographic variables and variables in arrhythmogenicity.

Inclusion criteria of the study were patients being over 18 years old, positive serology for Trypanosoma cruzi with at least two out of the three different techniques available (indirect immunofluorescence reaction, indirect hemagglutination and enzyme-linked immunosorbent assay (ELISA), being carriers of chronic Chagas cardiomyopathy, defined by the presence of increased left ventricle diastolic diameter (LVDd) (LVDd > $58 \mathrm{~mm}$ in men and LVDd > $52 \mathrm{~mm}$ in women ${ }^{28}$ ) and depressed LVEF (LVEF $<52 \%$ in men and $<54$ in women ${ }^{28}$ ). Exclusion criteria were refusal to sign the written consent term, make use of implantable cardioverter defibrillator (ICD) or pacemaker, atrial fibrillation or flutter, left bundle branch block and the presence of systemic diseases such as systemic arterial hypertension, coronary artery disease, rheumatic diseases, diabetes mellitus or glucose intolerance, renal insufficiency, chronic pulmonary obstructive disease, hydroelectrolytic disorders or significant anemia.

All patients were submitted to a medical examination, electrocardiogram, conventional echocardiography through the speckle tracking technique and two 24-hour dynamic electrocardiograms. All participants signed the written informed consent. The research project was evaluated and approved by the Research Ethics Committee of Universidade Federal de Minas Gerais (CAAE: 48354315.8.3001.5091).

\section{Electrocardiographic Evaluation}


The 12-lead electrocardiogram was recorded on a Hewlett Packard, model 1504, to select patients from the left bundle branch block (LBBB), atrial fibrillation and flutter who were excluded from the study ${ }^{29}$.

\section{Dynamic Electrocardiography (Holter System)}

The 24-hour electrocardiographic monitoring was performed using a 3-channel portable recording system (Dynamis, Cardios, São Paulo, Brazil). Patients were stimulated to do their normal activities during the recording period. Recordings were analyzed using the Burdick/DMI Hospital Holter System (Spacelabs Burdick Deerfield, WI, USA) through a semi-automatic technique and by an experienced cardiologist from Serviço de Cardiologia e Cirurgia Cardiovascular (Cardiology and Cardiovascular Surgery Service) of Hospital das Clínicas/ UFMG, where ectopic beats were coded and artifacts were excluded producing a consolidated report.

\section{Echocardiographic Study}

The echocardiographic study was conducted using Vivid Q and S6 systems (GE Vingmed Ultrasound AS system) and a commercially available software (EchoPAC; GE Healthcare, Milwaukee, WI). The LVEF was assessed using the Simpson's biplane method ${ }^{28}$.

Global longitudinal strain through standard views, apical four-chamber, two-chamber and long-axis views were obtained by speckle-tracking echocardiography. Three cardiac cycles from each view were recorded for offline analysis with a frame rate $>50$ frames/s. Peak negative strain was assessed in 16 LV segments, defined as the peak negative value throughout the cardiac cycle, including postsystolic shortening and the mean was defined as GLS. The time interval from the electrocardiographic onset of the Q/R wave to peak negative strain was assessed in each of the 16 LV segments. Mechanical dispersion was defined as the standard deviation of time to peak negative strain in the same 16 LV segments. Bull Eye's plots were constructed. Mitral inflow E velocity was recorded using pulsed Doppler. The e' velocity (tissue Doppler) was the mean of the septal and lateral mitral annuli and the E/e' ratio was measured. The echocardiographic studies were conducted by three echocardiographers.

\section{Statistical Analysis}

The database and the statistical analysis were carried out using the SPSS software version 20.0 (Statistical Package for Social Sciences). Parametric data were shown as means and standard deviation and compared to Student's $t$ test and chi-square test. Non-normal distribution data were studied by the median and variance and compared to the Mann-Whitney $\mathrm{U}$ test. Increased MD was defined as the primary outcome and the frequency and complexity of ventricular extrasystoles were defined as secondary outcomes. Spearman's correlation between MD and parameters of dynamic electrocardiography and echocardiography was evaluated.

Finally, in the univariate analysis, significant markers of MD and the density and complexity of ventricular extrasystoles were analyzed in a multivariate logistic regression model, together with gender and age of 
participants. Significance level was set at $5 \%$ and analyses were performed using the Statistical Package for the Social Sciences (SPSS) 20.0 software.

\section{Results}

\section{Population Study}

Seventy-seven outpatients who were clinically compensated (functional class according to NYHA classification I/II) were evaluated. General characteristics of patients were shown in Table 1. Mean age was 56 years and 46 patients were males $(60 \%)$. Most of the patients $(55.8 \%)$ were in NYHA functional class II and 34 patients were class I at the time of inclusion in the study. Sixty-five were on beta-blockers (84.4\%), 45 (58.4\%) angiotensin-converting enzyme inhibitors, 20 (26\%) angiotensin receptor blockers therapy, $36(46,8 \%)$ diuretics, $2(2,6 \%)$ digitalis and $17(22,1 \%)$ anticoagulants.

\section{Holter recordings}

The median VES (ou PVCs - premature ventricular contractions) from Holter recordings was 1423 (range 636 - 4272), 223 (4-101) paired VSV, 14 (1-229) bigeminismo VSV and NSVT 1 (0-3).

\section{Echocardiographic Parameter}

The analysis of variables obtained by the echocardiography are shown in Table 1 . The mean dimensions of left chambers (LVDd $=60 \mathrm{~mm}$ and LVSd $=46 \mathrm{~mm}$ ) were slightly increased and E/e' ratio was normal in all patients. Mean LVEF was $43 \%(35 \%-46 \%)$ in all patients and GLS was $14 \pm 3 \%$. Mean mechanical dispersion was increased in these patients reaching $60 \mathrm{~ms}$ (50 ms-80 ms).

\section{Correlation between mechanical dispersion, global longitudinal strain and ventricular extrasystoles on}

\section{4h Holter.}

According to the results shown in Table 1, a significant correlation was seen between MD and global longitudinal strain $(R=-0.696 ; p<0.001)$ (Chart 1$)$, whereas no significant correlation was seen between MD and LVEF $(R=-0.247 ; p<0.032)$. Mechanical dispersion was still correlated LVDd $(R=0.266 ; p<$ $0.021)$ and $\operatorname{LSd}(\mathrm{R}=0.250 ; p<0.266)$. No correlation was seen regarding $\mathrm{E} / \mathrm{e}^{\prime}(\mathrm{R}=0.128 ; p<0.184)$.

Regarding ventricular extrasystoles, MD showed a positive correlation $(R=0.317 ; p=0.005)$ (Figure 1$)$ as well as the paired extrasystoles $(R=0.349 ; p=0.002)$, with a moderate correlation with the presence of NSVT $(R=0.411 ; p=0.001)$.

In the logistic regression, MD was the only variable associated with the presence of paired VES (OR 1.05; CI 95\%: $1.003-1.099, p=0.038$ ) and bigeminy (OR 1.03; Cl 95\%: $1.001-1.058 p=0.044)$. Regarding the presence of NSVT, MD and GLS were statistically significant in univariate analysis $(p<0.01), M D$ being the only independently associated with NSVT (OR 1.04; Cl 95\%: $1.004-1.201, p=0.031$ ) (Figure 1) (Table 3). 
Table 1: Characteristics of the sample evaluated $(n=77)$.

\begin{tabular}{|c|c|c|}
\hline Variables & & Values \\
\hline Age (years) & & $55.8 \pm 10.4$ \\
\hline Males, n (\%) & & $46(59.7)$ \\
\hline \multirow[t]{2}{*}{ NYHA Functional class, n (\%) } & I & $34(44.2)$ \\
\hline & II & $43(55.8)$ \\
\hline \multicolumn{3}{|l|}{ Medications, n (\%) } \\
\hline Diuretic & & $36(46.8)$ \\
\hline ACE inhibitor & & $45(58.4)$ \\
\hline AT2-receptor inhibitor & & $20(26)$ \\
\hline Digitalis & & $2(2.6)$ \\
\hline Amiodarone & & $37(48.1)$ \\
\hline Anticoagulant & & $17(22.1)$ \\
\hline Beta-blocker & & $65(84.4)$ \\
\hline ASA & & $12(15.6)$ \\
\hline \multicolumn{3}{|l|}{ ECG Parameters } \\
\hline VES (n) & & $1423(636-4272)$ \\
\hline Paired VES (n) & & $23(4-101)$ \\
\hline Bigeminy (n) & & $14(1-229)$ \\
\hline NSVT (n) & & $1(0-3)$ \\
\hline \multicolumn{3}{|l|}{ Echocardiographic Parameters } \\
\hline LVDd (mm) & $60(57-65)$ & \\
\hline LVSd (mm) & $46(43-52)$ & \\
\hline $\mathrm{E} / \mathrm{e}^{\prime}$ ratio & $9(8-13)$ & \\
\hline LVEF (\%) & $43(35-46)$ & \\
\hline GLS $(\%) * *$ & $14 \pm 3$ & \\
\hline $\mathrm{MD}(\mathrm{ms})$ & $60(50-80)$ & \\
\hline
\end{tabular}

NYHA, New York Heart Association; ACE angiotensin-converting-enzyme inhibitor; ASA, acetylsalicylic acid.

VES, ventricular extrasystole; NSVT, nonsustained ventricular tachycardia; LVDd, left ventricular diastolic diameter; LVSd, left ventricular systolic diameter; LVEF, left ventricular ejection fraction; GLS, global longitudinal strain; MD, mechanical dispersion. Data are expressed as mean \pm SD or as a number (percentage).

Data are expressed as median (25\%-75\%) since they are not normal.

** Only variable that is normal and therefore is presented as mean $\pm \mathrm{SD}$

Table 2: Correlation between MD and electro- and echocardiographic parameters in the sample evaluated. 


\begin{tabular}{ccc}
\hline Variable & p-value & Correlation Coefficient (rho) \\
\hline Total VES & $\mathbf{0 . 0 0 5 * *}$ & 0.317 \\
Paired VES & $\mathbf{0 . 0 0 2 ^ { * * }}$ & 0.349 \\
\hline Bigeminy & $\mathbf{0 . 0 2 4 ^ { * }}$ & 0.257 \\
\hline NSVT & $\mathbf{0 . 0 0 1 * *}$ & 0.411 \\
\hline LVEF & $\mathbf{0 . 0 3 2 *}$ & -0.247 \\
\hline LVDd & $\mathbf{0 . 0 2 1 *}$ & 0.266 \\
\hline LVSd & $0.031^{*}$ & 0.250 \\
\hline E/e' ratio & 0.128 & 0.184 \\
\hline GLS & $<0.001 * *$ & -0.696 \\
\hline
\end{tabular}

VES, ventricular extrasystoles; NSVT, nonsustained ventricular tachycardia; LVDd, left ventricular diastolic diameter; LVSd; left ventricular systolic diameter; LVEF, left ventricular ejection fraction.

**significant Spearman's correlation at the level of $1 \%$.

*significant Spearman's correlation at the level of $5 \%$

Table 3: Univariate and multivariate analyses to identify variables associated with the presence of NSVT

\begin{tabular}{|c|c|c|c|c|c|c|}
\hline & \multicolumn{3}{|c|}{ Univariate Logistic Regression } & \multicolumn{3}{|c|}{ Multivariate Logistic Regression } \\
\hline & OR & CI $95 \%$ & p-value & OR & CI $95 \%$ & p-value \\
\hline \multicolumn{7}{|l|}{ Presence of NSVT } \\
\hline Age & 1.003 & $0.960-1.047$ & 0.905 & & & \\
\hline Gender & 1.659 & $0.661-4.164$ & 0.281 & & & \\
\hline NYHA & 0.654 & $0.264-1.622$ & 0.359 & & & \\
\hline LVEF & 0.961 & $0.905-1.022$ & 0.206 & & & \\
\hline LVDd & 1.029 & $0.962-1.101$ & 0.401 & & & \\
\hline LVSd & 1.023 & $0.966-1.084$ & 0.434 & & & \\
\hline LA & 1.046 & $0.946-1.157$ & 0.377 & & & \\
\hline $\mathrm{E} / \mathrm{e}^{\prime}$ ratio & 1.074 & $0.965-1.195$ & 0.193 & & & \\
\hline Diffuse hypokinesis & 0.682 & $0.216-2.156$ & 0.514 & & & \\
\hline GLS & 0.839 & $0.730-0.964$ & 0.013 & 0.976 & $0.815-1.076$ & 0.788 \\
\hline MD & 1.043 & $1.013-1.074$ & 0.005 & 1.040 & $1.004-1.201$ & 0.031 \\
\hline
\end{tabular}

\section{Discussion}

This study demonstrated that MD correlates with arrhythmogenicity in patients with chagasic cardiomyopathy with mild to severe left ventricular systolic dysfunction. MD was significantly and independently associated with VA events, even in patients with LVEF $>35 \%$. 
The presence of myocardial fibrosis has been demonstrated in several studies as an arrhythmogenic substrate ${ }^{31,32}$. This fibrosis causes heterogeneous ventricular activation. In Chagas cardiomyopathy, there is a change in the disposition of myocardial fibers due to collagen deposition, scar formation and remodeling, increasing myocardial heterogeneity ${ }^{13,33}$. Cardiac imaging play an important role in assessing the structural substrate for arrhythmogenicity ${ }^{34,35}$. Previous studies have shown that fibrosis is present in patients with Chagas cardiomyopathy and that the extension of the fibrosis in myocardial magnetic resonance (MR) imaging is correlated to the risk for arrythmias ${ }^{19}$. Echocardiogram can also evaluate this arrhythmogenic substrate by measuring LVEF and, more recently, by speckle trackingderived parameters (MD e SLG) $36,37,38$.

Although, several studies in patients with ischemic cardiomyopathy ${ }^{41}$, dilated idiopathic cardiomyopathy 25 , hypertrophic cardiomyopathy ${ }^{42}$, including chagasic cardiomyopathy ${ }^{27}$, using MD, had similar results, no cross-section study in patients with chagasic cardiomyopathy has been conducted to assess association of MD with arrhythmogenicity. The MD was recently validated in a meta-analyses that concluded that can be used as a parameter to predict ventricular arrhytmias, more studies are still needed, especially in patients with LVEF> $35 \%$, asymptomatic or with NYHA I, branch block, atrial fibrillation and with pacemaker and $\mathrm{ICD}^{39}$. There is only one study employing the MD technique analyzed patients with Chagas cardiomyopathy ${ }^{27}$, despite important peculiarities of this condition, which distinguish it from other cardiomyopathies $4,7,43$. Barros e collaborators, employing the MD technique analyzed patients with Chagas cardiomyopathy ${ }^{27}$ showed that MD was more pronounced in patients with CCC and with ICD when compared to those without ICD. This cross-sectional study included 62 patients with Chagas disease who were separated in two groups, according to the presence and absence of ICD, aiming to evaluate whether GLS and MD are associated with malign ventricular arrhythmia. MD and GLS demonstrated a significant and independent association with malign arrhythmias. In the present study, MD was an echocardiographic variable with a significant association with the frequency and complexity of arrhythmias in Chagas cardiomyopathy.

In this article, MD was the only echocardiographic variable with a significant and independent association with the frequency and complexity of arrhythmias in Chagas cardiomyopathy. Therefore, this noninvasive method is likely to be useful to detect chagasic patients with malign arrhythmia, which makes it even more relevant due to the significant arrhythmogenicity of Chagas disease and the large number of patients with this disease that are candidates for an ICD implantation.

In our sample, LVEF did not have any association with the presence or complexity of arrhythmia, reinforcing the relative limitation of this method in the functional and prognostic evaluation of chagasic patients. Furthermore, the use of LVEF is believed not to constitute an accurate criterion to identify patients with a risk of malign arrhythmia, and may lead to inaccurate indications of ICD implantations, an expensive and invasive procedure and with a high psychological impact on patients $37,44,45,46$. Thus, it is important and necessary to develop tools able to, more accurately, stratify those patients with a higher 
risk of malign arrhythmias and/or sudden death, both in Chagas cardiomyopathy and in those with different etiologies.

Identifying noninvasive markers of ventricular arrhythmia may contribute to identifying subgroups of patients that deserve special medical attention, in addition to guiding medical practice aiming to prevent death. Improving arrhythmia risk predictor methodology in Chagas disease has direct clinical implications and may be transferred to medical practice.

\section{Limitations}

The study had an adequate sample size but is limited due to the fact that participants are outpatients and, most of them, are clinically compensated (functional class according to the NYHA classification I/II) and, also because all patients were seen at the same reference center. Multicenter studies are necessary to confirm the findings. Moreover, prospective studies with patients with Chagas cardiomyopathy should be conducted to compare echocardiographic parameters with clinical outcomes.

Most patients were using beta blockers and amiodarone, which may interfere with arrhythmogenicity and with ventricular contractility. For ethical reasons, these medications were not discontinued.

\section{Conclusion}

The present study has shown that MD measurement was the only echocardiographic variable studied that was associated with density and complexity of ventricular extrasystoles in patients with chronic Chagas cardiomyopathy. This study gains perspectives on the evaluation of this technique of the risk stratification of these patients from longitudinal studies.

\section{Declarations}

Funding The authors did not receive support from any organization for the submitted work.

Conflict of interest There is no potential conflict of interest relevant to this article exist.

\section{Compliance with ethical standards}

Conflict of interest The authors declare that they have no conflict of interest.

Ethical approval The research project was evaluated and approved by the Research Ethics Committee of Universidade Federal de Minas Gerais (CAAE: 48354315.8.3001.5091).

\section{References}

1. World Health Organization (WHO) (2010) Chagas disease: control and elimination. p. 1-4 
2. Schmunis GA, Yadon ZE (2010) Chagas disease: A Latin American health problem becoming a world health problem. Acta Trop [Internet]. Elsevier B.V. v. 115, p. 14-21.

http://dx.doi.org/10.1016/j.actatropica.2009.11.003

3. Coura JR (2007) Chagas disease: what is known and what is needed - A background article. Mem Inst Oswaldo Cruz, v. 102, p. 113-122. ISSN 0074-0276. https://doi.org/10.1590/S007402762007000900018

4. Rocha MO, Ribeiro AL, Teixeira MM (2003) Clinical management of chronic Chagas cardiomyopathy. Front Biosci 8:e44-e54

5. Biolo A, Ribeiro AL, Clausell N (2010) Chagas cardiomyopathy-where do we stand after a hundred years? Prog Cardiovasc Dis v 52:300-316

6. Ribeiro AL, Nunes MP, Teixeira MM, Rocha MOC (2012) Diagnosis and Management of Chagas Disease and Cardiomyopathy. Nat Rev Cardiol v 9:576-589. https://dx.doi.org/10.1038/nrcardio.2012.109

7. Rocha MOC, Nunes MCP, Ribeiro AL (2009) Morbity and Prognostic factors in Chronic Chagasic Cardiomyopathy. Men Inst Osvaldo Cruz, v. 104; p. 159-166

8. Oria J, Ramos J (1949) Alterações do parassimpático do coração nos portadores de megaesôfago. Arq Bras Cardiol 2:311-316

9. Rassi Júnior A, Rassi AG, Rassi SG, Rassi Júnior L, Rassi A (1995) Arritmias ventriculares na doença de Chagas. Particularidades diagnósticas, prognósticas e terapêuticas. Arq Bras Cardiol v 65(4):377-387

10. Bestetti RB, Muccillo G (1997) Clinical course of Chagas' heart disease: a comparison with dilated cardiomyopathy. Inter J Cardiology, v. 60; p. 187 - 93

11. Marin-Neto JA, Simões MA, Sarabanda AV (1999) Cardiopatia chagásica. Arq Bras Cardiol, v. 72, p. 247-63

12. Bestetti RB (2016) Chagas Heart Failure in Patients from Latin America. Radcliffe Cardiology v 9(1):1-3

13. Rossi MA (1998) Fibrosis and inflammatory cells in human chronic chagasic myocarditis: scanning electron microscopy and immunohistochemical observations. Int J Cardiol 66:183-194

14. Andrade ZA (1999) Immunopathology of Chagas disease. Mem Inst Oswaldo Cruz v 94:71-80

15. Andrade ZA (2000) Patologia da doença de Chagas. In: Brener Z, Andrade Z, Barral-Netto M (eds) Trypanosoma cruzi e Doença de Chagas, 2nd edn. Guanabarra Koogan, Rio de Janeiro, pp 201-230

16. Rossi MA, Ramos SG, Bestetti RB (2003) Chagas' heart disease: clinical-pathological correlation. Front Biosci v 8:e94-e109

17. Bogliolo L (1976a) Anatomic causes of cardiac insufficiency in chronic chagasic cardiomyopathy (myocarditis) studied in comparison to anatomic causes of cardiac insufficiency in other cardiopathies. Part I. Arq Bras Cardiol v 29:419-424 
18. Bogliolo L (1976b) As causas anatômicas da insuficiência cardíaca na cardiopatia (miocardite) chagásica crônica, estudadas comparativamente com as causas anatômicas da insuficiência cardíaca noutras patologias: Parte 2. Arq Bras Cardiol, v. 29, p. 479-483

19. Rochitte CE, Oliveira PF, Andrade JM, lanni BM, Parga JR, Avila LF, Kalil-Filho R, Mady C, Meneghetti JC, Lima JAC, Ramires JAF (2005) Myocardial delayed enhancement by magnetic resonance imaging in patients with Chagas' disease: a marker of disease severity. J Am Coll Cardiol, v. 46, p. 1553-8, 2005. https://doi.org/10.1016/j.jacc.2005.06.067

20. De Carvalho AC, Tanowitz HB, Wittner M, Dermietzel R, Roy C, Hertzberg EL, Spray DC (1992) Gap junction distribution is altered between cardiac myocytes infected with Trypanosoma cruzi. Circ Res v 70:733-742. https://doi.org/10.1161/01.res.70.4.733

21. Barbosa MP, Carmo ASL, Rocha MOC, Ribeiro ALP (2015) Ventricular arrhythmias in Chagas disease. Rev Soc Bras Med Trop v 48:4-10. https://doi.org/10.1590/0037-8682-0003-2014

22. Haugaa KH, Smedsrud MK, Steen T, Kongsgaard E, Loennechen JP, Skjaerpe T, Voigt JU, Willems R, Smith G, Smiseth OA, Amlie JP, Edvardsen T (2010) Mechanical Dispersion Assessed by Myocardial Strain in Patients After Myocardial Infarction for Risk Prediction of Ventricular Arrhythmia. J Am Coll Cardiol Img v 3, 247-256. https://doi.org/ 10.1016/j.jcmg.2009.11.012

23. Haugaa KH, Amlie JP, Berge KE, Leren TP, Smiseth OA, Edvardsen T (2010) Transmural differences in myocardial contraction in long-QT syndrome: Mechanical consequences of ion channel dysfunction. Circulation v 122:1355-1363. https://doi.org/10.1161/CIRCULATIONAHA.110.960377

24. Teske AJ, De Boeck BWL, Melman PG, Sieswerda GT, Doevendans PA, Cramer MMC (2007) Echocardiographic Quantification of Myocardial Function Using Deformation Imaging, a Guide to Image Acquisition and Analysis Using Tissue Doppler and Speackle Tracking. Cardiovascular Ultrassound 5:1-19

25. Haugaa HK, Goebel B, Dahlslett T, Meyer k, Jung C, Alexander Lauten A, Figulla HR, Poerner TC, Edvardsen T (2012) Risk Assessment of Ventricular Arrythmias in Patients With Nonischemia Dilated Cardio Myopathy by Strain Echocardiography. J Am Soc Echocardiographic 25:667-673. https://doi.org/10.1016/j.echo.2012.02.004

26. Haland TF, Almaas VM, Hasselberg NE, Saberniak J, Leren IS, Hopp E, Edvardsen T, Haugaa KH (2016) Strain echocardiography is related to fibrosis and ventricular arrhythmias in hypertrophic cardiomyopathy. Eur Heart J Cardiovasc Imaging, v.17, p. 613-21, 2016

27. Barros MVL, Leren IS, Edvardsen T, Haugaa KH, Carmo AAL, Thais AR, Lage TAR P, Nunes MCP, Rocha MOC, Ribeiro ALP (2016) Mechanical Dispersion Assessed by Strain Echocardiography Is Associated with Malignant Arrhythmias in Chagas Cardiomyopathy. J Am Soc Echocardiogr [Internet]. Elsevier Inc, v. 29, p. 368-74. http://dx.doi.org/10.1016/j.echo.2015.12.008

28. Lang RM, Badano LP, Mor-Avi V, Afilalo J, Armstrong A, Ernande L, Flachskampf FA, Foster E, Goldstein AS, Kuznetsova T, Lancellotti P, Muraru D, Picard MH, Rietzschel ER, Rudski L, Spencer KT, Tsang W, Voigt JU (2015) Recomendations for Cardiac Chamber Quantification by Echocardiography 
in Adults: Na Update from the American Society of Echocardiography and The European Association of Cardiovascular Imaging. J Am Soc Echocargiograf 28:1-39

29. Pastore C, Pinho J, Pinho C, Samesina N et al (2016) III Diretrizes da Sociedade Brasileira de Cardiologia sobre análise e emissão de laudos eletrocardiográficos. Arq Bras Cardiol [Internet], v. 106, p. 1-23. Available from: http://www.gnresearch.org/doi/10.5935/abc.20160054

30. Grupi CJ, Moffa PJ, Barbosa SA, Sanches PC, Barragan Filho EG, Bellotti MV et al (1995) Holter Monitoring in Chagas' Heart Disease. Sao Paulo Med J 113:835-840

31. Stevenson WG, Brugada P, Waldecker B, Zehender M, Wellens HJ (1985) Clinical, angiographic, and electrophysiologic findings in patients with aborted sudden death as compared with patients with sustained ventricular tachycardia after myocardial infarction. Circulation 71:1146-1152

32. Gomess VA, Alves GF, Hadlich M, Azevedo CF, Pereira IM, Santos CRF, Brasil PEAA, Sangenis LHC, Cunha AB, Xavier SS, Saraiva RM (2016) Analysis of regional left ventricular strain in patients with Chagas disease and normal left ventricular systolic function. J Am Soc Echocardiogr 29:679-688

33. Hsia HH, Marchlinski FE (2002) Characterization of the electroanatomic substrate for monomorphic ventricular tachycardia in patients with nonischemic cardiomyopathy. Pacing Clin Electrophysiol 25:1114-1127

34. Bertini M, Schalij MJ, Bax JJ, Delgado V (2012) Emerging role of multimodality imaging to evaluate patients at risk for sudden cardiac death. Circ Cardiovasc Imaging 5:525-535

35. Macatangay C, Viles-Gonzalez JF, Goldberger JJ (2017) Role of cardiac imaging in evaluating risk for sudden cardiac death. Card Electrophysiol Clin vol 9, p. 639-50

36. Grimm W, Christ M, Bach J, Muller HH, Maisch B (2003) Noninvasive arrhythmia risk stratification in idiopathic dilated cardiomyopathy: results of the Marburg Cardiomyopathy Study. Circulation vol 108, p. 2883-91

37. Delgado V, Bucciarelli-Ducci C, Bax JJ (2016) Diagnostic and prognostic roles of echocardiography and cardiac magnetic resonance. J Nucl Cardiol 23:1399-1410

38. Cheng S, Larson MG, McCabe EL, Osypiuk E, Lehman BT, Stanchev P et al (2013) Reproducibility of speckle-tracking-based strain measures of left ventricular function in a community-based study. $J$ Am Soc Echocardiogr 26:1258-1266

39. Kawakami H, Nerlekar N, Haugaa KH, Edvardsen T, Marwick TH (2019) Prediction of ventricular arrhythmias with left ventricular mechanical dispersion: A systematic review and meta-analysis. JACC Cardiovasc Imaging, p. 1-11

40. Haugaa KH, Edvardsen T, Leren TP, Gran JM, Smiseth OA, Amlie JP (2009) Left ventricular mechanical dispersion by tissue Doppler imaging: a novel approach for identifying high-risk individuals with long QT syndrome. Eur Heart J, v. 30, p. 330 - 7

41. Haugaa KH, Grenne BL, Eek CH, Ersbøll M, Valeur N, Svendsen JH et al (2013) Strain echocardiography improves risk prediction of ventricular arrhythmias after myocardial infarction. JACC Cardiovasc Imaging v 6:8, p. 841-850 n. 
42. Schnell F, Matelot D, Daudin M, Kervio G, Mabo P, Carré F, Donal E (2017) Mechanical Dispersion by Strain Echocardiography: A Novel Tool to Diagnose Hypertrophic Cardiomyopathy in Athletes. J Am Soc Echocardiogr 30:251-261

43. Rocha MOC, Teixeira MM, Ribeiro AL (2007) An update on the management of Chagas cardiomyopathy. Expert Rev Anti Infect Ther v 5:727-743

44. Bestetti RB, Freitas OC, Muccillo G, Oliveira JS (1993) Clinical and morphological characteristics associated with sudden cardiac death in patients with Chagas' disease. Eur Heart J 14:1610-1614

45. Martinelli Filho M, Siqueira SF, Moreira H, Fagundes A, Pedrosa A, Nishioka SD et al (2000) Probability of Occurrence of Life-Threatening Ventricular Arrhythmias in Chagas' Disease versus Non-Chagas' Disease. PACE, p. 1944-46

46. Bestetti BR, Cardinalli-Neto A (2008) Sudden Cardiac Death in Chagas' Heart Disease in the Contemporany Era. Inter J Cardiology, 9-17. https://doi.org/10.1016/j.ijcard.2008.05.024

\section{Figures}

$1 \mathrm{~A}$

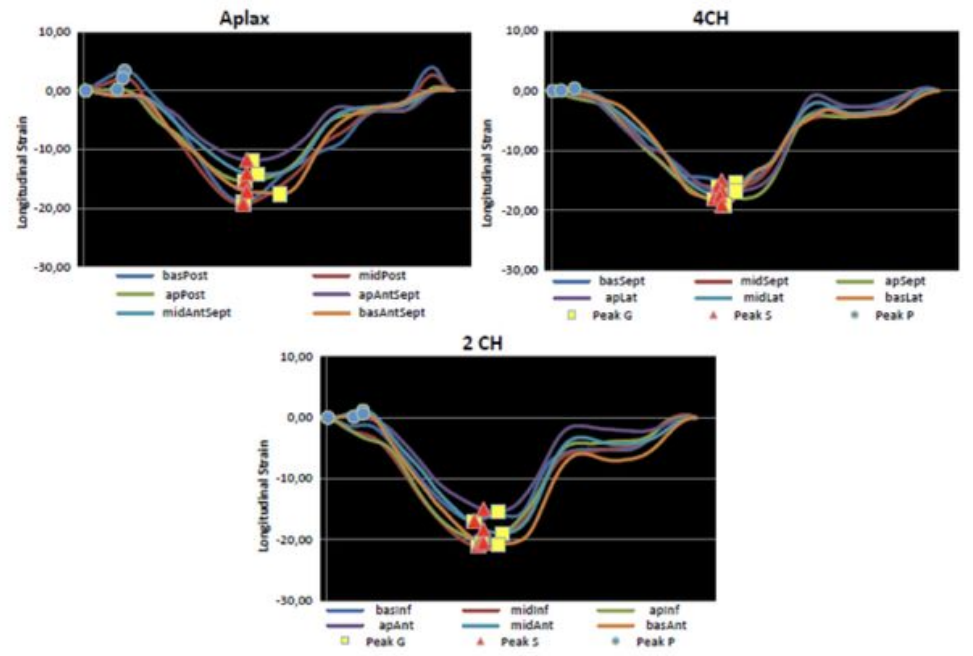

$1 B$
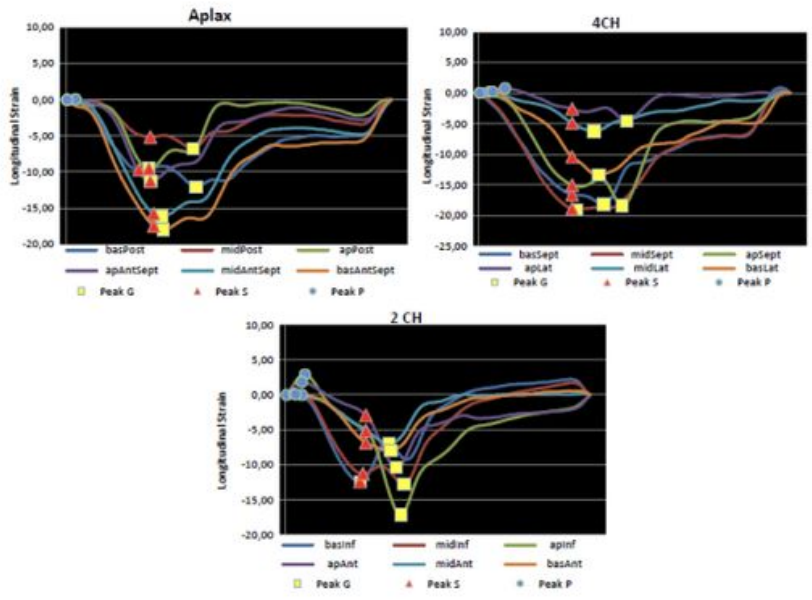

\section{Figure 1}

Strain curves from chagasic patients with (A) and without (B) ventricular taquycardia. Mechanical dispersion shows values of 40 and 85 ms respectively. 


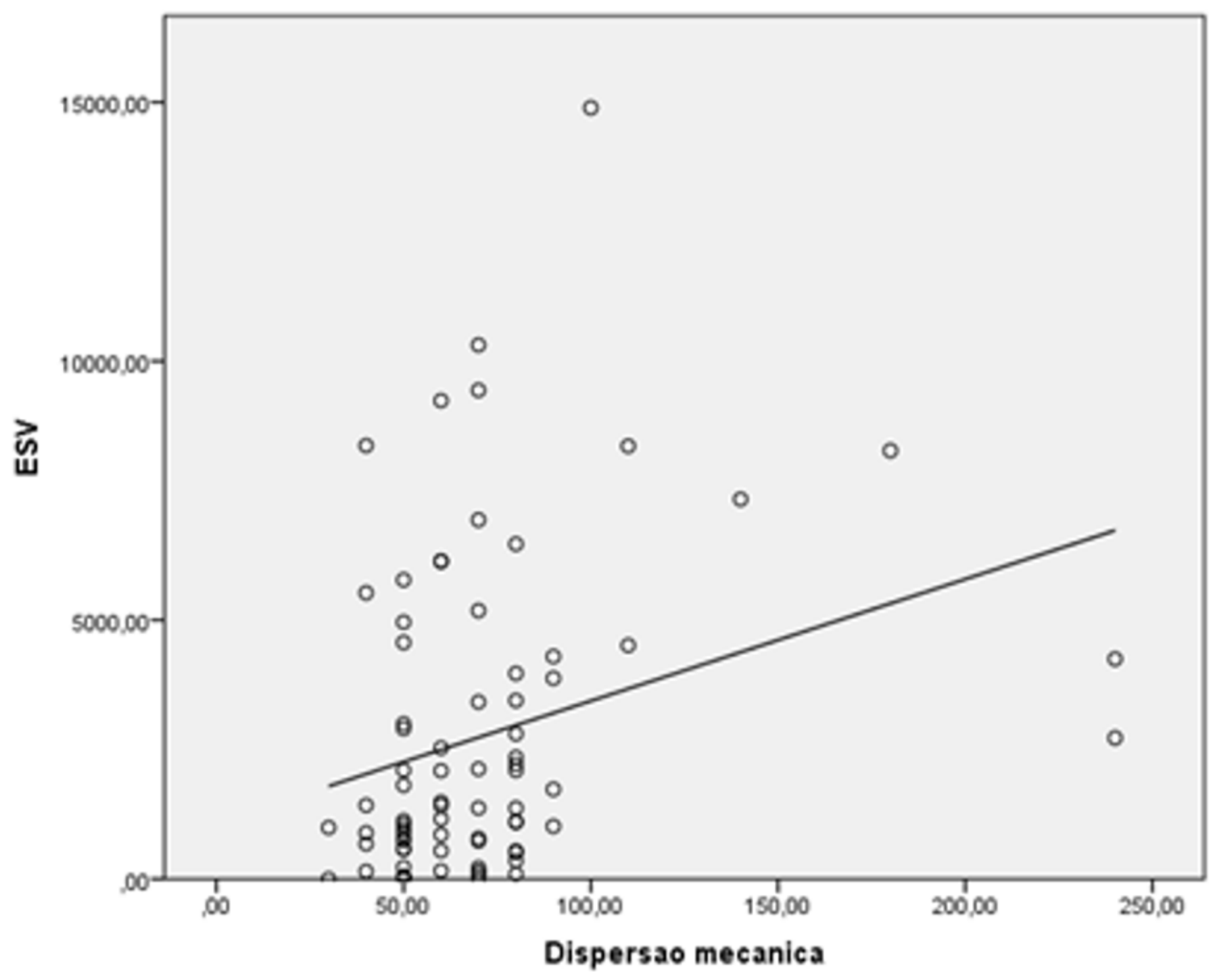

**Correlação rho $=0,317(p=0,005)$

Figure 2

Correlation between MD and VES. Correlation between MD (X-axis) and VES (Y-axis). MD, mechanical dispersion; VES, total number of ventricular extrasystoles. 